\title{
The end of a millennium
}

Despite the rapid and substantial changes we have undergone in the last decade of this century compared with the rest of the last 1000 years, the old values of trust, loyalty, family, honesty, friendship and integrity are just as important to people as they always were.

Mike Grace m.grace.bdj@bda-dentistry.org.uk

\section{This is the last issue of the BDJ in the twentieth century. Where will we be on the eve of the thirtieth century is totally beyond our wildest imaginings, let alone the end of the next century. But, to mark this occasion, I felt a personal reflection on this moment in time would be the most appropriate leader I could write for this issue.}

I find the concept of a thousand years quite difficult to grasp, rather like the distance to the stars or the length of time the dinosaurs existed on Earth. The fact that I, along with you, have lived through the end of one thousand years and the start of the next is,some would say, quite significant, yet paradoxically I find myself asking the 'So what?' question. What does it actually mean and is it really that significant?

The answer, like so many common-sense (but infuriating) answers is that it depends on what you are looking for. In terms of the existence of civilisation then a thousand years is an immense timespan with changes that are so remarkable that an individual from year 999 would find the world today inconceivable. Yet there is no doubt the millennium is being greeted (at the time of writing this on December 6th) with cynicism for the hype that has preceded the occasion and casual disregard by most people I speak to (in the UK at least).

Ask most people in the UK what the millennium means to them and they talk of the 'millennium bug' and the 'dome' with a resignation that comes from over-exposure. We are all tired of both, surely a reflection on the media coverage that today threatens to deaden us to innovation through constant repetition. Perhaps in the future we can learn that too much information can be as much a barrier to communication as too little.

Despite this cynicism, for some of us there is still an air of excitement over the future that seems to have been forgotten in the last-minute rush to midnight on December 31st. For us the question of what the $B D J$ will look like in the future is a subject of some fascination, not least because we may be setting the foundations for that change ourselves. Will paper in some format still be with us (as still seems likely to us today) or will some form of electronic media replace it? Or will something we cannot conceive of occur, such as direct transmission of relevant data into our brains so that we just somehow 'know' what we need to know without any effort? Perhaps of more relevance is whether we will still have dentitions that require care, and if so what role will there be for dentistry?

At the $B D J$ we are taking it in our stride. There is no special millennium issue, because I feel there is nothing significant enough in dentistry that has not already been said at some time recently or that we shall continue to report on. Apart from a slight change to the cover and contents we continue to publish the same journal, maintaining and improving on our quality as we have always done. But what we shall ensure we do is examine our own values and reflect on how to ensure that, when the next millennium comes round in 2999, if we are still here in some form or other the BDJ still stands by our own integrity in publishing and our objectives of increasing customer care and quality.

I used the term 'values' in the last paragraph because, for me, despite the rapid and substantial changes we have undergone in the last decade of this century compared with the rest of the last 1000 years, the old values of trust, loyalty, family, honesty, friendship and integrity are just as important to people as they always were. It may be corny, but it is still true. Values are still just that, what we think is important. I suspect many of them were around at the start of the current millennium (or at least I like to think so) and I hope they will still be around at the end of the next one. 